\title{
Isolation of cellulose nanocrystals from Gigantochloa scortechinii ASAM pulp
}

\begin{abstract}
ABSTRCT
This study aims to characterize the cellulose nanocrystals (CNC) isolated from alkaline sulfite anthraquinone and methanol (ASAM) bamboo (Gigantochloa scortechinii) pulp. The hydrolysis was carried out using $64 \%$ (w/w) sulfuric acid at $45^{\circ} \mathrm{C}$ for $45 \mathrm{~min}$. The $\mathrm{CNC}$ was subjected to field emission scanning electronic microscopy (FESEM), X-ray powder diffraction (XRD), Fourier transform infrared spectroscopy (FTIR), and transmission electron microscopy (TEM). The measurement of diameter for CNC was done by FESEM and TEM, which was in the range of 10-20 nm. The XRD and FTIR results exhibited that bamboo CNC has higher crystallinity index, $78 \%$ compared to bleached ASAM bamboo pulp, $60 \%$..
\end{abstract}

Keyword: Cellulose nanocrystals; Gigantochloa scortechinii. 